\title{
Salon
}

\section{Were polio to return, today...}

W hat would we do, today, were polio to return? For those too young to remember or old enough to have forgotten, in the early I950s the last polio pandemic swept the world. From Copenhagen, Denmark, to Vancouver, Canada, to Hong Kong, local medical teams mounted an unprecedented effort to sustain the lives of mostly young patients attacked by the disease. Gymnasiums were turned into wards, cots installed from wall to wall. Nursing and medical students were pressed into service to help maintain those whose respiratory paralysis could only be countered by manual ventilation after a tracheostomy.

Negative ventilation machines, "iron lungs" encasing patients from foot to chin were rushed into service for all those who might benefit from their use. There was no expectation that those saved would be returned to normalcy. That wasn't the point. The salvation of thousands of mostly young adults through a cumbersome process of mechanical ventilation was perceived as a major triumph in both medical circles and society-at-large.

The idea of not saving young polio patients wasn't considered. It would have been unthinkable to do less than everything possible. In the I950s the default assumption of medical ethics and society-at-large was that life was an absolute not a contingent value. As a society we therefore did not ask, "Can we afford it?" because there was no option but to do everything possible, irrespective of cost.

Were polio to return, or a similarly disabling pandemic that maimed but did not kill, would we save the victims? In the current environment of bioethics and cost accountancy the answer, I think, is ... no.

Since the I950s, sanctity of life as a principal value has been replaced by

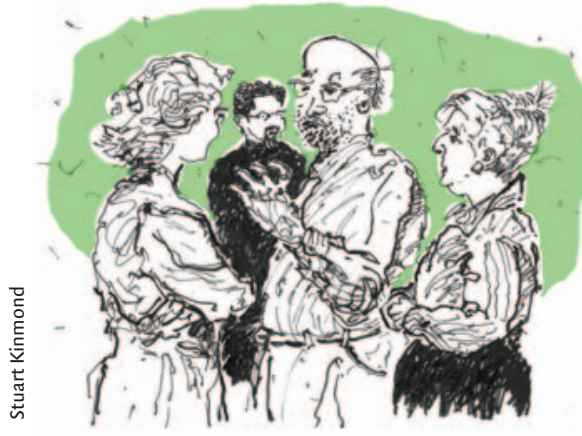

life as a contingent value depending on "quality" based on a standard of mundane normalcy. The result has been if not, as some suggest, a "licence to kill," at least a "licence to let die" persons with physical restrictions. In its extreme version the result has been what former governor Richard Lamm of the state of Colorado in the United States called a "duty to die" on the part of society's fragile. We want neither their bother nor the expense of their care.

The simple assumption is that life quality necessarily diminishes in a predictably linear fashion as physical limits increase. The result is an assumption, argued implicitly, that a severely restricted life is, finally, no life at all. To sustain this fiction we dismiss outof-hand myriad reports of valued life quality among those with physical limits. But then, why trust the presumably self-deluding judgments of persons with physical restrictions when we have a cost-efficient standard that says not saving those with severe restrictions is a favor to them and cost saving for us all?

Were polio to return today, mainstream bioethicists presumably would argue that the life quality of a person on ventilatory assistance was insupportable. "Nobody wants to live like that," they would say, despite thousands who have chosen it over dying. Ignored would be the very vocal protests of the many middle-aged men and women who remain among us, saved to society despite the paralytic ravages of polio contracted in the I950s.

Provincial health ministers would talk about the "tragedy" of these cases and the impossibility of marshalling public resources to assure the continuance of those who could be saved. And where would front-line physicians, who are paid by provincial health officials and are listening to bioethicists, stand on the necessity of care for those saved to permanent physical disability and extensive social support?

The public would cry foul, insisting upon the necessity of a "rescue principle" in the face of pandemic disease. What then would we do? Saving those we could, would give the lie to 30 years of policy and political posturing. To do otherwise would mean letting people die who could have saved. Either way, our priorities will be tested. And our ethics and practices might be reformed, not on the basis of bad economics and a juvenile medical ethic but upon the ideal of help - medicine's and society's - for those who need it most.

\section{Tom Koch PhD \\ Bioethicist}

Vancouver, BC

This is the revised and condensed text of a paper first presented at the American Society of Bioethics and the Humanities annual conference in Denver, Colo., in 2006. Tom Koch, a bioethicist, gerontologist and medical geographer, is the author of Cartographies of Disease.

Have you got an opinion about this article? Post your views at www.cmaj.ca. Potential Salon contributors are welcome to send a query to salon@cma.ca. 